\title{
EFEKTIVITAS LAYANAN INFORMASI DENGAN MENGGUNAKAN FILM IMPERFECT UNTUK MEREDUKSI SELF HARM PADA DIRI MAHASISWA
}

\author{
Maulina Indah Chahyani ${ }^{1}$, Maghfirotul Lathifah² \\ Maulinaindah91@gmail.com, maghfirotul@unipasby.ac.id \\ Universitas PGRI Adi Buana Surabaya
}

\begin{abstract}
This study aims to determine the effectiveness of information services using imperfect films to reduce self harm to students. This research approach is quantitative. This research is a type of preexperimental research design, one group pre-test post-test design. This study has two variables, namely the dependent variable or variable $X$ (information services with imperfect film media) and also the independent variable or variable $Y$ (self harm). The population in this study were students of BK a1 class of 2017 at PGRI AdiBuana University, Surabaya. The sample in this study used purposive sampling, namely there were 5 students who had the highest self harm score. The results of this study indicate that there is a decrease in the mean pre-test value of 64.60 to the mean post-test value of 53.40. So it can be concluded that the use of information services using imperfect films is significantly effective in reducing self harm.
\end{abstract}

Keywords: information service, film imperfect, self harm

\begin{abstract}
Abstrak
Penelitian ini bertujuan untuk mengetahui efektivitas layanan informasi dengan menggunakan film imperfect untuk mereduksi self harm pada diri mahasiswa. Pendekatan penelitian ini adalah kuantitatif. Penelitian ini merupakan jenis rancangan penelitian pra-eksperimen one group pre-test post-test design. Penelitian ini memiliki dua variabel yaitu terdiri dari variabel terikat atau variabel $X$ (layanan informasi dengan media film imperfect) dan juga variabel bebas atau variabel Y (self harm). Populasi dalam penelitian ini yaitu mahasiswa BK a1 angkatan 2017 Universitas PGRI AdiBuana Surabaya. Sampel dalam penelitian ini menggunakan purposive sampling yaitu terdapat 5 mahasiswa yang memiliki skor self harm tertinggi. Hasil penelitian ini menunjukkan terdapat penurunan nilai mean pre-test 64,60 menjadi nilai mean post-test 53,40. Sehingga dapat disimpulkan penggunaan layanan informasi dengan menggunakan film imperfect secara signifikan efektif dalam mereduksi self harm.
\end{abstract}

Kata Kunci: layanan informasi, film imperfect, self harm

\section{PENDAHULUAN}

Mahasiswa unipa surabaya ditemukan banyak mahasiswa yang memiliki kebiasaan saat banyak pikiran seperti stres karena tugas, putus cinta, masalah dengan orang tua atau keluarga, permasalahan dengan teman, merasakan kesedihan yang mendalam yang disebabkan oleh insecure dan patah hati, frustasi dan lain-lain yang mereka tidak bisa ungkapkan maka dari itu mereka meluapkan atau mengekpresikan dengan banyak makan, menahan lapar seharian bahkan bisa lebih. Hal ini yang banyak ditemukan di lingkungan mahasiswa unipa Surabaya.

Mahasiswi yang mengalami stres karena tugas, putus cinta, permasalahan dengan teman, masalah dengan orangtua atau keluarga, masalah perekonomian, frustasi, kesedihan yang mendalam yang mereka tidak bisa ceritakan kepada orang lain. Hal yang mereka lakukan untuk meungkapkan atau mengekspresikan yaitu dengan makan-makanan secara berlebihan, tidak makan seharian bahkan bisa lebih dari sehari. Permasalahan yang ditemukan oleh peneliti di lapangan menunjukan bahwa hal tersebut merupakan self harm.

Self harm merupakan tindakan menyakiti dirinya sendiri yang terjadi sebagai respons terhadap kesusahan, stres, dan frustasi yang dialami seseorang (Polling et al., 2020). Self harm atau melukai diri sendiri merupakan masalah kesehatan mental yang sering terjadi di masyarakat 
terutama diusia remaja kemudian dari masalah self harm ini ditemukan lebih banyak yang melakukannya adalah perempuan daripada laki-laki (Hawton et al., 2012). Seseorang yang melakukan self harm sering kali tidak menyadari apa yang mereka alami dan mereka tidak tahu mengapa mereka melakukan hal itu, kebanyakan seseorang yang melakukan self harm merasa kesendirian (Taylor et al., 2009).

Peneliti mempelajari tindakan self harm yang disengaja sebagai fenomena perilaku bukan sebagai gejala gangguan kepribadian ambang (Klonsky et al., 2003). Self harm merupakan tindakan melukai diri sendiri namun tidak mengakibatkan kerusakan jaringan tubuh misalnya makan berlebih, tidak makan seharian hal tersebut berada di bawah definisi menyakiti self harm yang biasa (Skegg, 2005). Internet bisa jadi pemicu terjadinya self harm pada seseorang namun internet juga bisa berpotensi menjadi sumber daya yang berguna yaitu sebagai tempat orang-orang yang mengalami self harm mencari dukungan dan nasihat (Romeu et al., 2020).

Pengertian self harm menurut para ahli dapat disimpulkan Self harm ialah perilaku seseorang yang sengaja menyakiti dirinya sendiri tetapi masih bisa bertahan hidup meliputi; berfikir negatif,prilaku negatif, interaksi sosial, emosional contohnya makan berlebihan, tidak makan seharian bahakan bisa lebih. Hal tersebut sebagai ungkapan rasa stress yang dirasakan karena tugas, patah hati, masalah dengan orangtua atau keluarga, masalah dengan teman, frustasi yang tidak bisa diungkapkan dengan lisan. Emosi negatif dirasakan ini kemudian bisa mendorong seseorang untuk melakukan self harm lagi karena butuh untuk menghilangkan rasa negatif itu akan terus keulang (Ibunda, 2019).

Akibatnya bila self harm tidak segera ditangani, maka individu tersebut akan susah mengontrol emosinya dan akan selalu melampiaskan ke hal yang negatif seperti fenomena self harm yang ditemukan peneliti di lapangan seperti makan secara berlebihan, tidak makan seharian, menggoreskan tangan, meminum obat-obatan, membenturkan kepala ke tembok. Akibat lainnya mereka akan terusmenerus memendam perasaan yang dia alami tanpa mau menceritakan hal yang dialami ke orang lain dan akan susah berkomunikasi dengan baik kepada orang lain disekitarnya. Dampak negatif lainnya jika individu yang mengalami self harm tidak segera ditangani maka hal yang paling berbahaya bisa jadi mereka melakukan percobaan bunuh diri karena self harm disebabkan oleh emosi yang sudah lama di pendam, depresi, stres, frustasi.

Komponen program BK yaitu terdapat layanan responsif. Berdasarkan permendikbud nomer 111 tahun 2014 layanan responsif yaitu memberikan bantuan kepada siswa yang memiliki masalah khusus yang harus segera ditangani. Kemudian layanan informasi yaitu teknik pemberian informasi atau layanan informasi sering juga disebut dengan metode ceramah, yaitu pemberian penjelasan oleh seorang pembicara kepada sekelompok pendengar. Pelaksanan layanan informasi yaitu tahap perencanaan, pelaksanaan, dan penilaian (Permendikbud, 2014). faktor yang menyebabkan individu melakukan perilaku melukai diri sendiri atau self-harm adalah faktor mekanisme pertahanan diri dalam strategi coping yang negatif. Masa kecil seseorang yang mengalami trauma psikologis, kurangnya kasih sayang dari keluarga terutama ayah dan ibu, tidak adanya komunikasi yang baik dalam keluarga, permasalahan yang terjadi di lingkungan masyarakat, permasalahan dengan teman, kejadian buruk yang pernah dialami di masa lalu dan stres karena terlalu banyak masalah dalam menjalani kehidupan (Whitlock, 2009).

Penggunaan film imperfect karena didalam film tersebut memiliki masalah yang complicated, pertama terjadinya perbedaan perhatian, kasih sayang yang diberikan ibu terhadap anak pertama dan kedua, yang kedua adanya bullying secara nonverbal yang didapatkan pemeran utama yang dilakukan oleh teman-teman ditempat dia berkerja. Hal-hal tersebut yang membuat pemeran utama dalam film imperfect ini tanpa dia sadari melakukan self harm karena emosi,sakit hati, kesedihan yang mendalam yang dia rasakan dilampiaskan dengan memakan coklat dengan jumlah yang banyak. Kemudian karena 


\section{Efektor, Volume 8 Issue 2, 2021, Pages 184 - 189 \\ Maulina Indah Chahyani, Maghfirotul Lathifah}

persaingan kantor dia mau melakukan dietnamun diet yang dilakukan sangatlah berbahaya sampai menyebabkan dia masuk Rumah Sakit.

Kerucut pengalaman yang dikemukakan oleh Edgar Dale menyatakan pengetahuan dapat diperoleh dari kejadian atau pengalaman langsung yang dilihat dan pengalaman tidak langsung seperti dari buku. Semakin nyata objek yang dipelajari, maka semakin akurat pengetahuan yang diperoleh dan semakin tidak langsung pengetahuan itu diperoleh maka semakin abstrak pengetahuan individu, maka dari pengertian yang dinyatakan oleh edgar dale (Sanjaya, 2009).

Dengan film imperfect dijadikan media paling efektif untuk menyampaikan sesuatu yang sering terjadi dikehidupan nyata yang disebabkan berkembangnya internet terlebih lagi penggunaan media sosial yang tidak bijak sering terjadi bully seperti body shiming yang karena berkembangnya media sosial yang semakin gampang seseorang mengomentari terutama komentar negatif yang membuat seseorang menjadi bisa melakukan self harm (Prakasa, 2019).

Peneliti menggunakan film imperfect karena peneliti melihat banyak sekali faktor-faktor yang sama yang bisa menyebabkan seseorang melakukan self harm. Dari penggunaan film imperfect peneliti berharap mahasiswi menyadari bahwa yang mereka lakukan merupakan self harm yang bisa saja membahayakan dirinya jika tidak segera di sadari dan ditangani. Jika mahasiswi menyadari dan mau memperbaiki dirinya maka hal yang akan terjadi mereka akan mudah bergaul dilingkungan sosialnya, kemudian mudah berkomunikasi dengan orang lain tanpa ada yang ditutup-tutupi seperti mulai mau meceritakan dengan jelas apa yang dia rasakan kepada orangtua, saudara, teman dan guru.

\section{METODE PENELITIAN}

Penelitian ini menggunakan desain penelitian quasi-eksperimental pre-test and post test design (Alan, clarke \& ruth, n.d.) yang dijabarkan pada gambar 3.1 di bawah ini

Pre-test treatment post-test

\begin{tabular}{|lll}
\hline $\mathrm{T}_{1}$ & $\mathrm{X}$ & $\mathrm{T}_{2}$ \\
\hline
\end{tabular}

\section{Gambar 1. Rancangan Penelitian One Group Pre-Test-Post-Test Design}

Keterangan:

1. T1 adalah pretest (pengukuran variabel terikat yaitu self harm dengan menggunakan skala pengukuran yang dikembangkan oleh peneliti)

2. $\mathrm{X}$ adalah treatment (pemberian layanan informasi dengan menggunakan fim imperfect 3 kali dengan alokasi waktu 45 menit)

3. T2 adalah posttest (pengukuran variabel terikat yaitu self harm dengan menggunakan skala pengukuran setelah kelompok subjek diberi layanan informasi dengan menggunakan film imperfect) 


\section{Efektor, Volume 8 Issue 2, 2021, Pages 184 - 189 \\ Maulina Indah Chahyani, Maghfirotul Lathifah}

Penelitian ini menggunakan populasi mahasiswa unipa Surabaya sebanyak 32 orang mahasiswa. pengambilan data adalah dengan menggunakan purposive sampling peneliti menetapkan 5 mahasiswi terpilih yang memenuhi kriteria dan memperoleh skor tinggi terhadap self harm.

Metode pengumpulan data penelitian ini yaitu dengan instrumen penelitian yang menggunakan skala pengukuran yaitu skala liket. Skala pengukuran self harm sudah diuji cobakan kepada 33 mahasiswa 2019 kemudian hasil akan di analisis dengan korelasi item soal untuk menguji validits butir item dengan menggunakan r-tabel dengan nilai validitas 0,34 . Kemudian analisis data pada penelitian ini adalah uji hipotesis menggunakan uji wilcoxon pada SPSS Versi 24.0

Tabel 1. Hasil pre test dan post test

\begin{tabular}{llll}
\hline Nama & Pre test & Perlakuan & Post test \\
\hline Eksperimen $(\mathrm{E})$ & 32 & $\mathrm{X} 1$ & 5 \\
Kontrol $(\mathrm{K})$ & 5 & $\mathrm{X} 2$ & 1 \\
\hline
\end{tabular}

\section{HASIL DAN PEMBAHASAN}

Pada penelitian ini data yang diperoleh setelah dilakukan pre-test akan diketahui berapa subyek yang akan mendapatkan treatmen layanan informasi dengan media film imperfect. Rentang penelitian pada skala pengukuran self harm mahasiswa dalam penelitaian ini terdapat rentang skor 3 dengan banyak item 17 butir pernyataan, sehingga kriteria interval tersebut dapat ditentukan dengan cara sebagai berikut :

\section{$\frac{\text { Skor tertinggi - skor terrendah }}{3}$}

Maka, untuk menentukan 3 katagori tersebut adalah:

$$
\begin{gathered}
\frac{68-39}{3} \\
9,6=10 \\
\text { Tinggi } 68-59 \\
\text { Sedang } 58-49 \\
\text { Rendah } 48-39
\end{gathered}
$$

Sebelum melakukan treatment layanan informasi menggunakan film imperfect peneliti memberikan pretest kepada 32 mahasiswa, kemudian mendapatkan hasil 5 mahasiswa yang mengalami self harm dengan skor tinggi. Berikut 5 mahasiswa yang menjadi sampel penelitian yang mengalami self harm tinggi.

Self harm yang terjadi pada mahasiswa dari hasil treatment yang telah dilakukan peneliti sebanyak 5 kali pertemuan. Pada bagian ini peneliti akan menyajiakan hasil yang telah diperoleh di tabel berikut. 
Efektor, Volume 8 Issue 2, 2021, Pages 184 - 189

Maulina Indah Chahyani, Maghfirotul Lathifah

Tabel 2: pre-test dan post-test self harm

\begin{tabular}{lllllll}
\hline No & $\begin{array}{l}\text { Nama } \\
\text { mahasiswa }\end{array}$ & Pre-test & Katagori & $\begin{array}{l}\text { Post- } \\
\text { test }\end{array}$ & Katagori & $\begin{array}{l}\text { Perbedaan } \\
\text { skor }\end{array}$ \\
\hline 1 & NNH & 68 & TINGGI & 43 & RENDAH & 25 \\
\hline 2 & SA & 65 & TINGGI & 56 & SEDANG & 9 \\
\hline 3 & PAPS & 63 & TINGGI & 54 & SEDANG & 9 \\
\hline 4 & RG & 65 & TINGGI & 63 & TINGGI & 2 \\
\hline 5 & KDK & 64 & TINGGI & 50 & SEDANG & 14 \\
\hline
\end{tabular}

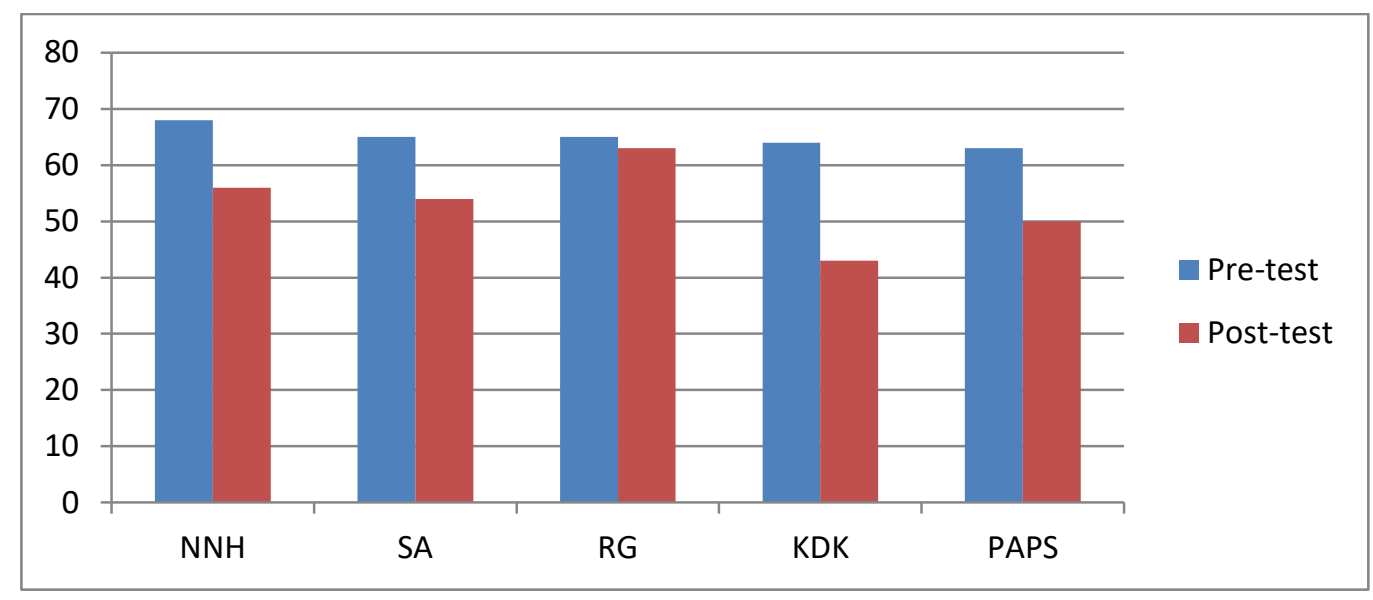

Gambar 2: Penurunan Self Harm

Penurunan variabel self harm pada mahasiswa yang terjadi pada 5 subjek penelitian, sebelum dan setelah diberikan treatment layanan informasi dengan menggunakan media film imperfect terjadi penurunan pada setiap subjeknya.

Perubahan dari katagori tinggi menjadi rendah dan sedang. Kondisi setiap mahasiswa mempengaruhi hasil perubahan yang terjadi setelah dilakukan treatment layanan informasi dengan menggunakan film imperfect untuk mereduksi self harm.

Perubahan pada penelitian ini juga dilihat dari penurunan nilai self harm pada hasil post-test setelah diberikan treatment layanan informasi dengan menggunakan film imperfect untuk mereduksi self harm, nilai pre-test sebelum dilakukan treatment yaitu 68 , sedangkan nilai post-test yaitu setelah dilakukan treatment mendapatkan hasil 43 disini dapat dilihat terdapat penurunan self harm dengan itu penggunaan layanan informasi dengan menggunakan film imperfect secara signifikan efektif dalam mereduksi self harm.

Analisis data untuk mengetahui efektivitas layanan informasi dengan menggunakan film imperfect dapat mereduksi self harm dilakukan dengan analisis non parametric dengan uji Wilcoxon menunjukkan bahwa rendahnya skor dengan dilakukannya treatment layanan informasi dengan menggunakan film imperfect untuk mereduksi self harm lebih menurun daripada sebelum dilakukan treatment. Berdasarkan hasil perhitungan diperoleh Asymp. Sig $=0,042<\alpha=0,05$ maka Ha di terima artinya penggunaan layanan informasi dengan menggunakan film imperfect secara signifikan efektif dalam mereduksi self harm. 
Efektor, Volume 8 Issue 2, 2021, Pages 184 - 189

Maulina Indah Chahyani, Maghfirotul Lathifah

\section{SIMPULAN}

Berdasarkan hasil penelitian bahwa penggunaan layanan informasi dengan menggunakan film imperfect secara signifikan efektif dalam mereduksi self harm. hal tersebut dapat dilihat dari hasil tabeltabel diatas yang sesuai dengan hasil proses dan tujuan treatment. Kemudian, dapat dilihat dari hasil treatment bahwa kelima mahasiswa mengalami penurunan self harm. Kemudian juga hasil perhitungan diperoleh Asymp. Sig $=0,042<a=0,05$ maka Ha di terima artinya penggunaan layanan informasi dengan menggunakan film imperfect secara signifikan efektif dalam mereduksi self harm.

\section{DAFTAR RUJUKAN}

Alan, clarke \& ruth, D. (n.d.). Evaluation Research: An Introduction to Principles, Methods and Practice Alan Clarke, Ruth Dawson - Google Buku.

https://books.google.co.id/books?id=4_FTxELbSbwC\&printsec=frontcover\&dq=evaluation+researc h\&hl=id\&sa=X\&ved=2ahUKEwj8sK-

z7vTrAhU4lbcAHcvxB2gQ6AEwAXoECAYQAg\#v=onepage\&q=evaluation research\&f=false

Hawton, K., Saunders, K. E. A., \& Connor, R. C. O. (2012). Suicide 1 Self-harm and suicide in adolescents. The Lancet, 379(9834), 2373-2382. https://doi.org/10.1016/S0140-6736(12)60322-5

Ibunda. (2019). self harm bukan pilihan. https://youtu.be/lCnAhTalRnw

Klonsky, E. D., Oltmanns, T. F., \& Turkheimer, E. (2003). Deliberate self-harm in a nonclinical population: Prevalence and psychological correlates. American Journal of Psychiatry, 160(8), 1501-1508. https://doi.org/10.1176/appi.ajp.160.8.1501

Permendikbud. (2014). Permendikbud tahun 2014 no. 111 tentang bimbingan dan konseling. Kementerian.

Polling, C., Woodhead, C., Harwood, H., Hotopf, M., \& Hatch, S. L. (2020). "There Is So Much More for Us to Lose If We Were to Kill Ourselves": Understanding Paradoxically Low Rates of Self-Harm in a Socioeconomically Disadvantaged Community in London. Qualitative Health Research. https://doi.org/10.1177/1049732320957628

Prakasa, E. (2019). imperfect. https://youtu.be/HE3XOWv0HgA

Romeu, D., Guthrie, E., Brennan, C., Farley, K., \& House, A. (2020). Online resources for people who self-harm and those involved in their informal and formal care: Observational study with content analysis. International Journal of Environmental Research and Public Health, 17(10). https://doi.org/10.3390/ijerph17103532

Sanjaya, W. (2009). Strategi Pembelajaran Berorientasi Standar Proses Pendidikan (Kencana (ed.)). Skegg, K. (2005). Seminar Self-harm. 366.

Taylor, T. L., Hawton, K., Fortune, S., \& Kapur, N. (2009). Attitudes towards clinical services among people who self-harm: Systematic review. British Journal of Psychiatry, 194(2), 104-110. https://doi.org/10.1192/bjp.bp.107.046425

Whitlock, J. (2009). The cutting edge: non-suicidal self-injury in adolescence. ... Facts and Findings. Online Verfügbar Unter: ..., May. 